\title{
A comparative study of fine-needle aspiration cytology and histopathology in salivary gland lesions
}

\author{
Vaidya $\mathrm{S}^{1}$, Sinha $\mathrm{A}^{1}$, Narayan $\mathrm{S}^{1}$, Adhikari $\mathrm{S}^{2}$, KC Sabira ${ }^{1}$ \\ ${ }^{1}$ Departments of Pathology, BP Koirala Institute of Health Sciences, Dharan, Nepal \\ ${ }^{2}$ Departments of Surgery, BP Koirala Institute of Health Sciences, Dharan, Nepal
}

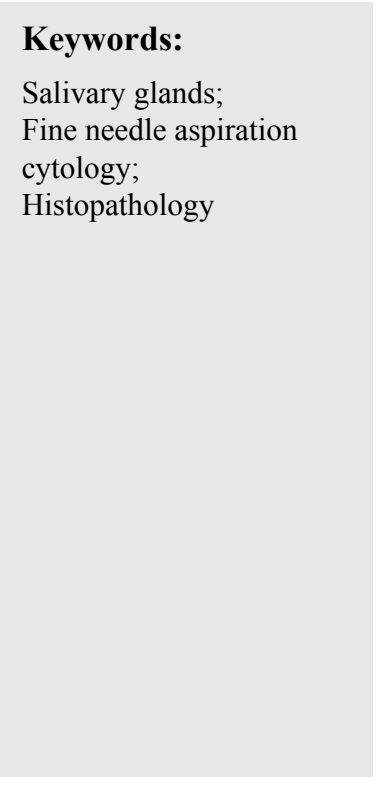

\begin{abstract}
Background: A wide variety of benign and malignant tumours originate in the salivary glands and insufficient tumour cells make their diagnosis difficult in some patients. The aim of this study was to evaluate the efficacy of fine-needle aspiration cytology in the diagnosis of salivary gland lesions and to correlate cytological findings with histopathology.

Materials and Methods: This was a prospective study done from September 2002 to May 2004. Fine needle aspiration cytology was performed in 58 patients with clinically significant salivary gland masses.

Results: Fine needle aspiration cytology categorized $67.24 \%$ of the salivary gland lesions as neoplastic and $32.76 \%$ as non-neoplastic lesions. Amongst the neoplastic lesions, $76.9 \%$ were benign and $23.1 \%$ were malignant cases. Histopathological examination revealed that $81.05 \%$ of the cases were benign and $18.95 \%$ were malignant. Fine needle aspiration cytology had a sensitivity, specificity and diagnostic accuracy of $81.82 \%, 100 \%$ and $96.55 \%$, respectively. The positive predictive value and negative predictive value was $100 \%$ and $95.9 \%$, respectively.

Conclusion: Fine needle aspiration of the salivary gland is a safe and reliable technique in the primary diagnosis of salivary gland lesions. Although, limitations are encountered while predicting specific lesions on cytology, especially when dealing with cystic and some malignant lesions, this study has shown that fine needle aspiration cytology has a high sensitivity, specificity and diagnostic accuracy in diagnosing salivary gland lesions.
\end{abstract}

\section{INTRODUCTION}

Salivary gland tumours are uncommon, corresponding to approximately $3-10 \%$ of neoplasms of the head and neck regions. ${ }^{1,2}$ However, a wide variety of benign and malignant tumours that can originate in these glands and insufficient tumour cells make their diagnosis difficult in some patients. ${ }^{3}$

\section{Correspondence:}

Dr. Sujan Vaidya, $M D$

Department of Pathology, Patan Hospital, Lalitpur, Nepal.

E-mail:vaidyasujan@yahoo.co.uk.
Therefore, the primary challenge of fine needle aspiration cytology (FNAC) is differentiating benign from malignant disease, then differentiating the various malignancies. The preoperative information is used to plan the most effective therapeutic approach.

The aim of the present study was to evaluate the efficacy of FNAC in diagnosis of salivary gland lesions and to correlate cytological findings with histopathology. 


\section{MATERIALS AND METHODS}

This was a prospective study conducted in the Departments of Pathology and Surgery, in B.P. Koirala Institute of Health Sciences (BPKIHS), Dharan, Nepal, between September 2003 and May 2004. A total of 58 patients with salivary gland lesions who had undergone preoperative FNAC and had been diagnosed by subsequent histopathological examination were included in this study.

The FNAC was performed using a 23-gauge needle attached to a $10 \mathrm{ml}$ disposable syringe. Aspirates were smeared on clean slides, wet fixed or air dried and stained by Papanicolaou (PAP) and May-Grunwald-Giemsa (MGG) stains. The excised surgical specimens were fixed in $10 \%$ formalin, then routinely processed and stained by Haematoxylin and Eosin (HE) stain.

We compared the histopathological findings with the preoperative cytology of the FNAC specimens and calculated the sensitivity, specificity, positive predictive value (PPV) negative predictive value (NPV), and overall accuracy of FNAC for diagnosing benign and malignant diseases. Data analysis was based on Galen and Gambino method to calculate sensitivity and specificity of FNAC in differentiating between benign and malignant lesions.

\section{RESULTS}

Age of the patients ranged from 6-73 years with a median age of 38 years. However, most malignant cases $45.5 \%$ ) were seen after the age of 60 . The parotid and the submandibular glands were the two most frequently involved sites in this study, each accounting for $46.5 \%$ of the cases, followed by minor salivary glands $(5.2 \%)$. The sublingual gland was involved in 1 case $(1.7 \%)$. Of the 47 cases diagnosed in histology as benign, most were seen in the submandibular gland $(53.2 \%)$ followed by the parotid $(40.4 \%)$. Most malignant cases (11 cases, $72.7 \%$ ) were diagnosed in the parotid followed by submandibular gland (18.2\%).

The results of FNAC were broadly categorized into inflammatory lesions, benign cystic lesions, benign neoplasms and malignant neoplasms. Of the 58 cases (49, $84.5 \%$ ) were benign and 9 cases (15.5\%) were malignant. Also, amongst the 58 cases, 39 cases $(67.2 \%)$ were neoplastic while 19 cases (32.8\%) were non-neoplastic. Table 1 shows the FNAC diagnoses in 58 cases. In 8 cases, fluid was aspirated but a specific cytological diagnosis could not be reached. Such lesions were assessed to be benign in nature and were categorized as benign cystic lesions.

\section{Histology and cytohistological correlation}

Of the 58 cases, $49(84.5 \%)$ cases were benign and $9(15.5 \%)$ cases were malignant. There were 2 false negative cases but no false positive cases. The histopathological diagnoses are shown in Table 2.

Pleomorphic adenoma (fig. 1A, B\&C) was the most common salivary gland tumour followed by warthin tumor (fig. 2). Amongst the malignancies, acinic cell carcinoma, mucoepidermoid (fig.3) and polymorphous low grade adenocarcinoma was more common than other tumors like infiltrating salivary duct carcinoma (fig.4), epithelialmyoepithelial carcinoma (fig.5), myoepithelial carcinoma, papillary carcinoma and adenoid cystic carcinoma.

Overall, for diagnosing salivary gland lesions (benign and malignant tumours combined), the sensitivity, specificity and diagnostic accuracy of FNAC were $81.82 \%, 100 \%$ and $96.55 \%$, respectively. The positive predictive value (PPV)

Table 1. FNAC diagnoses of salivary gland lesions

\begin{tabular}{llll}
\hline & Diagnosis & \multicolumn{1}{l}{ Total } & \multicolumn{1}{c}{$\%$} \\
\hline \multirow{4}{*}{ Benign } & Benign cystic lesions & 8 & $13.8 \%$ \\
\cline { 2 - 4 } & Chronic sialadenitis & 11 & $18.9 \%$ \\
\cline { 2 - 4 } & Pleomorphic adenoma & 24 & $41.5 \%$ \\
\cline { 2 - 4 } & Basal cell adenoma & 2 & $3.4 \%$ \\
\cline { 2 - 4 } & Warthin's tumour & 3 & $5.2 \%$ \\
\cline { 2 - 4 } & Lymphangioma & 1 & $1.7 \%$ \\
\hline \multirow{3}{*}{ Malignant } & Total & $\mathbf{4 9}$ & $\mathbf{8 4 . 5 \%}$ \\
\cline { 2 - 4 } & Mucoepidermoid carcinoma & 3 & $5.2 \%$ \\
\cline { 2 - 4 } & Adenocarcinoma & 1 & $1.7 \%$ \\
\cline { 2 - 4 } & Acinic cell carcinoma & 3 & $5.1 \%$ \\
\hline & Adenoid cystic carcinoma & 2 & $3.5 \%$ \\
\hline & Total & $\mathbf{9}$ & $\mathbf{1 5 . 5 \%}$ \\
\hline & Grand total & $\mathbf{5 8}$ & $\mathbf{1 0 0} \%$ \\
\hline
\end{tabular}

Table 2: Histopathological diagnoses of salivary gland lesions

\begin{tabular}{|c|c|c|c|}
\hline & Histolopathological diagnosis & Total & $\%$ \\
\hline \multirow{6}{*}{ Benign } & Chronic sialadenitis & 13 & $22.4 \%$ \\
\hline & Sialadenosis & 2 & $3.5 \%$ \\
\hline & Basal cell adenoma & 2 & $3.5 \%$ \\
\hline & Pleomorphic adenoma & 24 & $41.4 \%$ \\
\hline & Warthin's tumour & 6 & $10.4 \%$ \\
\hline & Total & 47 & $81.1 \%$ \\
\hline \multirow{10}{*}{ Malignant } & Infiltrating salivary duct carcinoma & 1 & $1.7 \%$ \\
\hline & Papillary adenocarcinoma & 1 & $1.7 \%$ \\
\hline & Acinic cell carcinoma & 2 & $3.5 \%$ \\
\hline & Epithelial- myoepithelial carcinoma & 1 & $1.7 \%$ \\
\hline & Mucoepidermoid carcinoma & 2 & $3.5 \%$ \\
\hline & Adenoid cystic carcinoma & 1 & $1.7 \%$ \\
\hline & Polymorphous low-grade carcinoma & 2 & $3.5 \%$ \\
\hline & Myoepithelial carcinoma & 1 & $1.7 \%$ \\
\hline & Total & 11 & $18.9 \%$ \\
\hline & Grand total & 58 & $100 \%$ \\
\hline
\end{tabular}


Table 3: Cytohistological correlation of benign salivary gland lesions

\begin{tabular}{lcccc}
\hline Histological diagnosis & No of cases & \multicolumn{3}{c}{ FNAC diagnosis } \\
\cline { 3 - 5 } & & Exactly categorized & Benign but not exactly categorized & False-positive \\
\hline Chronic sialadenitis & 13 & 10 & 3 & - \\
\hline Sialadenosis & 2 & - & 2 & - \\
\hline Basal cell adenoma & 2 & 2 & - & - \\
\hline Pleomorphic adenoma & 24 & 23 & 1 & - \\
\hline Warthin's tumour & 6 & 3 & 3 & - \\
\hline Total & $\mathbf{4 7}$ & $\mathbf{3 8}$ & $\mathbf{9}$ & - \\
\hline
\end{tabular}

Table 4: Cytohistological correlation of malignant salivary gland tumours

\begin{tabular}{lcccc}
\hline Histological diagnosis & No of cases & \multicolumn{2}{c}{ FNAC diagnosis } \\
\cline { 2 - 5 } & & Exactly categorized & Malignant but not exactly categorized & False-negative \\
\hline Infiltrating salivary ductal Ca & 1 & - & 1 & - \\
\hline Papillary adenocarcinoma & 1 & 1 & - & - \\
\hline Acinic cell Ca & 2 & 2 & - & - \\
\hline Epithelial-myoepithelial Ca & 1 & - & 1 & - \\
\hline Mucoepidermoid Ca & 2 & 2 & - & - \\
\hline Adenoid cystic ca & 1 & 1 & - & - \\
\hline Polymorphous low-grade Ca & 2 & - & 1 & 1 \\
\hline Myopepithelial Ca & 1 & - & - & 1 \\
\hline Total & $\mathbf{1 1}$ & $\mathbf{6}$ & $\mathbf{3}$ & $\mathbf{2}$
\end{tabular}

Table 5: Cytohistological correlation with other studies

\begin{tabular}{|c|c|c|c|c|c|c|}
\hline First author & No. of cases & Diagnostic accuracy & Sensitivity & Specificity & PPV & NPV \\
\hline Jayaram $\mathrm{G}^{5}$ & 53 & $73.6 \%$ & $90 \%$ & $95 \%$ & - & - \\
\hline Das $^{6}$ & 712 & $91 \%$ & $94.6 \%$ & $75 \%$ & - & - \\
\hline Stramandinoli $\mathrm{RT}^{7}$ & 79 & $82.3 \%$ & $68.2 \%$ & $87.7 \%$ & $68.2 \%$ & $87.7 \%$ \\
\hline Piccioni $\mathrm{LO}^{8}$ & 176 & $97 \%$ & $81 \%$ & $99 \%$ & $93 \%$ & $98 \%$ \\
\hline Iqbal $\mathrm{M}^{9}$ & 49 & $96.4 \%$ & $62.5 \%$ & $96.97 \%$ & - & - \\
\hline Stow $\mathrm{N}^{10}$ & 104 & $92.3 \%$ & $86.9 \%$ & $92.3 \%$ & $96.8 \%$ & $86.6 \%$ \\
\hline Postema RJ ${ }^{11}$ & 380 & $96 \%$ & $88 \%$ & $99 . \%$ & $95 \%$ & $97 \%$ \\
\hline Rehman $\mathrm{H}^{12}$ & 50 & $78 \%$ & $53.28 \%$ & $88.57 \%$ & $72.7 \%$ & $79.9 \%$ \\
\hline Lukas $\mathrm{J}^{13}$ & 107 & 89.2 & $85.0 \%$ & $97.5 \%$ & & \\
\hline This study & 58 & $96.55 \%$ & $81.82 \%$ & $100 \%$ & $100 \%$ & $95.9 \%$ \\
\hline
\end{tabular}

was $100 \%$ and the negative predictive value (NPV) was $95.9 \%$.

An accurate specific lesion prediction for both benign and malignant lesions combined by FNAC was achieved in $75.86 \%(44 / 58)$ of the cases.

\section{Benign lesions}

For benign lesions, the sensitivity, specificity and diagnostic accuracy of FNAC were $100,81.8 \%$ and $96.6 \%$, respectively. The PPV for benign disease was $95.9 \%$ and the negative predictive value (NPV) was $100 \%$. An accurate specific lesion predicition for these lesions was achieved in $80.9 \%$ (38 cases, Table 3 ).

Pleomorphic adenoma was the commonest lesion in this study. FNAC had a sensitivity of $95.83 \%$, specificity of $97.05 \%$ and a diagnostic accuracy $96.55 \%$ in diagnosing this tumour. An accurate lesion predicition for pleomorphic adenoma was seen in $95.83 \%$ (23) cases. 


\section{Malignant lesions}

The sensitivity, specificity and diagnostic accuracy of FNAC for diagnosing malignant salivary gland tumours were $81.8 \%, 100 \%$ and $96.6 \%$, respectively. The positive predictive value (PPV) was $100 \%$ and the negative predictive value (NPV) was $95.9 \%$. An accurate specific lesion predicition for these lesions was achieved in $54.6 \%$ (6 cases, Table 4$)$.
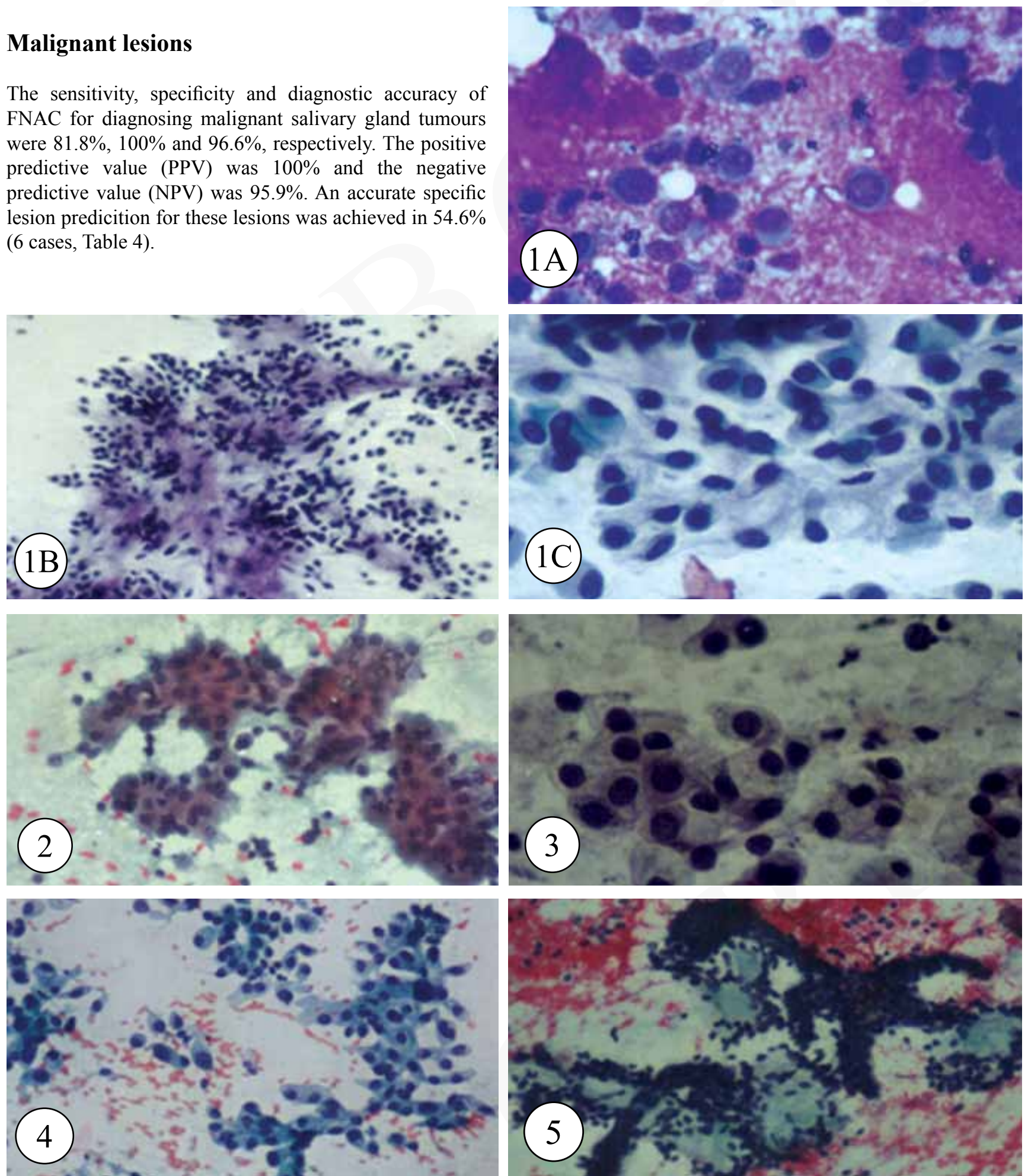

Figure 1A: Mixture of epithelial cells and myxoid stroma in pleomorphic adenoma (MGG stain, X 400).

Figure 1B: Myxoid stromal tissue with admixed epithelial cells in pleomorphic adenoma (Pap stain, X100).

Figure 1C: Plasma cell-like pattern in pleomorphic adenoma (Pap stain, X400).

Figure 2: Monolayered clustersof oxyphilic cells and scattered lymphocytes in the background in Warthin's tumour (Pap stain, X200).

Figure 3: Intermediate cells with abundant and vacuolated cytoplasm in mucoepidermoid carcinoma (Pap stain, X400).

Figure 4: Loosely cohesive clusters of malignant cells with large pleomorphic nuclei and abundant cytoplasm in salivary duct carcinoma (Pap stain, X100).

Figure 5: Clusters of epithelial cells with scanty cytoplasm and large stromal hyaline globules in epithelial-myoepithelial carcinoma (Pap stain, X100). 


\section{DISCUSSION}

FNAC is a safe and reliable and relatively painless procedure for the preoperative diagnosis of the salivary gland lesions. ${ }^{4}$

In our study, a high diagnostic efficacy of FNAC in diagnosing both benign and malignant lesions was achieved. Overall, for benign and malignant lesions, combined, FNAC showed a sensitivity of $81.8 \%$, specificity of $100 \%$ and an overall diagnostic accuracy of $96.6 \%$. These results were comparable to previously reported results (Table 5). ${ }^{5-13}$

Although a high diagnostic efficacy of FNAC in diagnosing salivary glands was achieved in this study, an accurate lesion prediction in typing specific histological lesions was achieved in only $80.6 \%$ of benign lesions and $54.5 \%$ of malignant lesions. A lower diagnostic accuracy of FNAC in typing specific benign lesions was observed in this study while aspirating cystic lesions (8 cases). These lesions were cytologically categorized as benign cystic lesions, as no features of malignancy were seen in their respective smears.

Of the 8 cystic lesions, 3 cases each were diagnosed on histology as Warthin's tumour and chronic sialadenitis and a case each were diagnosed as a pleomorphic adenoma and polymorphous low-grade adenocarcinoma. Postema et $\mathrm{al}^{11}$ also observed similar findings when diagnosing cystic lesions, and concluded that cytologic diagnosis of "cysts" should be interpreted with caution.

Of the 11 malignancies, 2 were misdiagnosed in cytology as benign (Table 4). One was a case of polymorphous low grade adenocarcinoma (PLGA), which was diagnosed on cytology as a benign cystic lesion. The aspirate of the lesion yielded $2 \mathrm{ml}$ of straw coloured fluid, which on microscopic examination showed foamy macrophages and few ductal cells only. The other false-negative result was reported in a case of myoepithelial carcinoma, which was reported on cytology as a pleomorphic adenoma. Review of the slides showed cellular smears, comprising of epithelial cell clusters in a chondromyxoid background.

The reason for low lesion prediction in typing specific malignant salivary gland lesions is due to the fact that a large number of benign and malignant neoplasms arise in the salivary glands and as there is considerable overlap of morphological features of these lesions causing diagnostic difficulties. Also, in new entities like polymorphous lowgrade adenocarcinoma, cytological diagnosis is still not characterized. ${ }^{14}$

In this study, the maximum number of patients presenting with salivary gland lesions $(29.3 \%)$ and the maximum number of benign lesions (31.9\%) were seen in the 21-30 years age group. Most of the malignancies were seen in the fifth and sixth decades. Similar observations were found in other studies. ${ }^{15-17}$ No sex preponderance was noticed in the overall incidence of salivary gland lesions in this study. Similar reports have been reported by others. ${ }^{16,18}$

The proportion of non-neoplastic lesions in the present study $(22.4 \%)$ is similar to that reported by Jayaram et $\mathrm{al}^{5}$ and Cardillo et al. ${ }^{19}$ As in other studies, pleomorphic adenoma was also the most common salivary gland lesion in this study, followed by Warthin's tumour. ${ }^{6,15,20}$ Amongst the malignancies, acinic cell carcinoma, mucoepidermoid and polymorphous low grade adenocarcinoma was more common than the others, The incidence of malignant salivary gland tumours in the literature are variable. In a study by Postema et $\mathrm{al}^{11}$ acinic cell carcinoma was most common while it was adenoid cystic carcinoma in studies by Akhter et al ${ }^{15}$ and Stewart et al. ${ }^{21}$

\section{CONCLUSION}

FNAC of the salivary gland is a safe and reliable technique in the primary diagnosis of salivary gland lesions. Although, limitations are encountered while predicting specific lesions on cytology, especially when dealing with cystic and some malignant lesions, this study has shown that FNAC has a high sensitivity, specificity and diagnostic accuracy in diagnosing salivary gland lesions.

\section{REFRENCES}

1. Everson JW, Cawson RA. Salivary gland tumours. A review of 2410 cases with particular reference to histological types, site, age and sex distribution. J Pathol 1985;46:51-8.

2. Calearo C, Pastore A, Storchi OF, Polli G. Parotid gland carcinoma: analysis of prognostic factors. Ann Otol Rhinol Laryngol 1998;107:969-73.

3. Fulciniti F, Califano L, Zupi A, Vetrani A. Accuracy of fine needle aspiration biopsy in head and neck tumours. J Oral Maxillofac Surg. 1997;55:1094-7.

4. Shaha AR, Webber C, DiMaio T, Jaffe BM. Needle aspiration biopsy in salivary gland lesions. Am J Surg. 1990;160:373-6.

5. Jayaram G, Dashini M. Evaluation of fine needle aspiration cytology of salivary glands: an analysis of 141 cases. Malays J Pathol. 2001; 23:93-100.

6. Das DK, Petkar MA, Al-Mane NM, Sheikh ZA, Mallik MK, Anim JT. Role of fine needle aspiration cytology in the diagnosis of swellings in the salivary gland regions: A study of 712 cases. Med Princ Prac 2004;13:95-106.

7. Stramandinoli RT, Sassi LM, Pedruzzi PAG et al. Accuracy, sensitivity and specificity of fine needle aspiration biopsy in salivary gland tumours: A retrospective study. Med Oral Pathol Cir Bucal 2010;15:32-7.

8. Piccioni LO, Fabiano B, Gemma M, Sarandria D, Bussi M. Fine needle aspiration cytology in diagnosis of parotid lesions. Acta Otorhinolarygol Ital. 2011;31:1-4.

9. Iqbal M, Anwar K, Ihsanullah, Mohammad J, Khan IA, Hussain G. The diagnostic value of fine needle aspiration cytology in masses of the salivary glands. JPMI 2011;25: 73-7.

10. Stow N, Veivers D, Poole A. Fine -needle aspiration cytology in the management of salivary gland lesions: an Australian experience. Ear Nose Throat J. 2004;83:128-31.

11. Postema RJ, van Velthuysen MLF, van den Brekel MWM, Balm 
AJM, Peterse JL. Accuracy of fine needle aspiration cytology of salivary gland lesions in the Netherlands Cancer Institute. Head Neck 2004;26:418-24.

12. Rehman H, Khan MS, Wahid F, Ahmad I. A profile of parotid gland tumours from a tertiary care hospital in Peshawar. JPMI 2011;25:15862.

13. Lukas J, Duskova J. Fine-needle aspiration biopsy in the diagnosis of tumors and non-neoplastic lesions of salivary glands. Bratisl Lek Listy. 2006;107:12-5.

14. Sahai K, Kapilas K, Dahiya S, Verma K. Fine needle aspiration cytology of minor salivary gland tumours of the palate. Cytopathology 2002;13:309-16.

15. Akhter J, Hirachand S, Lakhey M. Role of FNAC in the diagnosis of salivary gland swellings. KUMJ 2008;6:204-8.
16. Nagarkar N, Bansal S, Dass A, Singhal SK, Mohan H. Salivary gland tumour- our experience. Indian J Otolaryngol Head Neck Surg 2004;56:31-4.

17. Spiro RH. Management of malignant tumours of the salivary glands. Oncol Huntingt 1998;12:671-80.

18. Sengupta S, Roy A, Mallick et al. FNAC of salivary glands. Indian J Otolaryngol Head Neck Surg 2002;54:184-8.

19. Cardillo MR. Salivary gland masses: The diagnostic value of fine needle aspiration cytology. Arch Anat Cytol Pathol 1990;38:26-32.

20. Young JA, Smallman LA, Proops TDW, Johnson AP. Fine needle aspiration cytology of salivary gland lesions. Cytopathology 1990;5:25-33.

21. Stewart CJR, MacKenzie K, McGarry GW, Mowat A. Fine needle aspiration cytology of salivary gland: review of 341 cases. Head Neck 2000;22:139-46. 